\title{
Profiles of tourists participating in shark cage diving in Gansbaai, South Africa
}

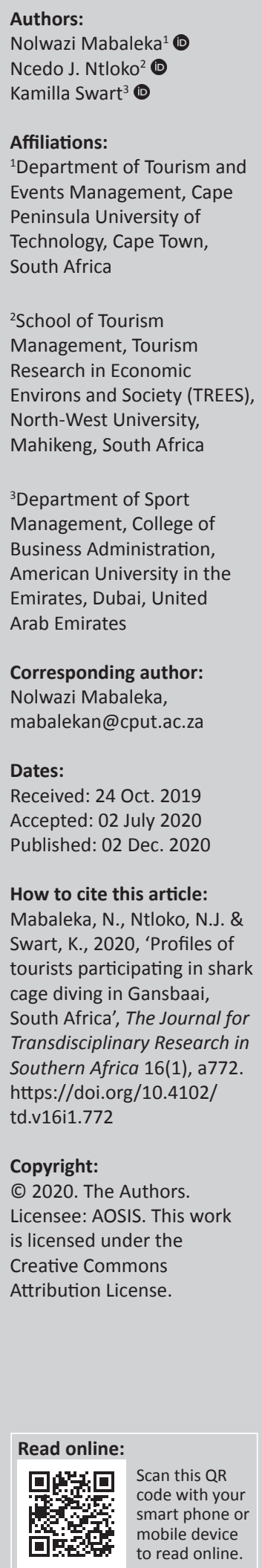

Coastal and marine tourism is a sector that draws visitors from around the globe to South Africa. This is largely because of an array of marine wildlife resources found in the country. Despite this strong pull factor, there is limited information on the economic value of the marine environment. This article focuses on establishing the profiles of visitors taking part in shark cage diving in Gansbaai. Such profiling will facilitate the understanding of the potential target market of CMT visitors to Gansbaai, whilst contributing towards targeted developments in the area aimed at capturing the economic value of such visitors through the provision of a range of visitor-specific activities to make the destination more appealing. It will also contribute to further developments in the area, in providing a wide range of activities to make the destination more appealing. In ascertaining the profile of visitors, a quantitative research design was adopted. A total of $n=378$ self-administered questionnaires were collected from visitors taking part in shark cage diving using a face-to-face proportionate sampling technique. The results revealed that a majority of visitors were drawn to Gansbaai because of shark cage diving and that a large portion travelled to Gansbaai for holiday purposes. There was a challenge in the ability of the destination to attract overnight visitors because of a limited product offering in the area. As a result, minimal spending occurs in Gansbaai as an overwhelming majority of the visitors are day visitors. These results have implications for tourists, tourism destination planners, tour operators and tourism establishments in Gansbaai.

Keywords: tourists profile; coastal and marine tourism; shark cage diving; operation phakisa; marine protected areas.

\section{Introduction}

The tourism industry has been globally recognised as an important driver of change and a key to economic prosperity for developing nations. As stated by Statistics South Africa (2018), 96.2\% of foreign arrivals into the country were for leisure purposes. This emphasises the significance of South Africa as a major holiday destination with an immense opportunity for growth. According to Grant Thornton (2018), the aim of the government is to strengthen the contribution of tourism to the Gross Domestic Product (GDP) of South Africa to R499 billion by 2020. As stated by Aguiló Perez and Juaneda (2000:627) and Vainikka (2013:270), a tourist would normally choose a destination where there is a sea-side venue for his or her holiday. This further highlights South Africa as a strong player in this regard as the country boasts $3000 \mathrm{~km}$ coastline with an array of marine wildlife (Operation Phakisa 2014). Coastal and Marine Tourism (CMT) is ranked amongst the top four sub-sectors of the maritime sector, with a contribution of R19 b in the year 2013 to the country's GDP (South African Maritime Safety Authority - SAMSA 2016). This emphasises the phenomenal potential which could be achieved by this sector and a justification for further development.

For most communities, particularly in disadvantaged countries, coastal and marine ecosystems have played a significant role as a means of survival (Lange \& Jiddawi 2009:251). South Africa is no exception. Falling within non-urban coastal areas, Gansbaai is a small town along the Whale Coast in the Western Cape with a large concentration of Southern Right Whales and Great White Sharks (SA Venues 2016). Gansbaai has also been labelled as 'the great white capital of the world' and attracts a large number of tourists to the area (Gansbaai Info 2016). According to Mograbi and Rogerson (2007:91), diving has been considered as a type of niche activity in South Africa. Shark cage diving, therefore, falls within this category and is a well-recognised water-based activity in the country (Cape Town Magazine 2016).

The profiling of tourists is important where sustainable tourism is concerned, as this assists the operators to have a clear understanding of their clients and the services they desire (Moscardo, 
Woods \& Saltzer 2004:232). Having a clear understanding of the profile of visitors, thus, leads to designing operators' packages that meet or even exceed customer expectations. As alluded to by Marques, Reis and Menezes (2010:973), the profiling of visitors is a complex task because of the forever changing social settings. This, therefore, suggests that operators have to constantly study their visitors in order to keep up with such changes and keep their clients satisfied.

According to Mihajlovic and Koncul (2016:920), various models have been implemented and changed throughout history in order to adapt to changes in consumer behaviours. Stynes (1997:15) noted an increase in curiosity regarding the economic impacts of tourism from businesses and public organisations. This indicated that economic analyses could influence decision-making in tourism. Thus, the models and approaches discussed in this article form the basis of the conceptual framework of the study, which looks at visitor spending patterns to determine the motivation and profile of the visitors. Frechtling (1994:430) indicates that in order to measure economic impacts, secondary data from economic base models, Input-Output (I-O) model multipliers, government economic statistics and visitor spending surveys should be analysed. The I-O model provides multipliers which can be utilised to estimate economic efforts of an economy (Bess \& Ambargis 2011:2). When estimating economic impacts using the I-O model, three categories are considered namely, direct, indirect and induced impacts thus providing ways to estimate the changes in activity in a particular economy (Stynes 1997:11). Although the I-O model has been widely used across the globe, it is also well known for its limitations such being too expensive to carry and being demand-driven (Fernando et al. 2015:3). In order to overcome these limitations, a more sophisticated model known as the computable general model (CGE) was adopted. What makes the CGE more suitable than the I-O model is its ability to model markets for goods and services, factor consumer spending as well as to recognise resource limitations. Tourism Satellite Accounts (TSA) and cost benefit analysis (CBA) are models designed to also measure the goods and services associated with the economic impact of tourism to economies (European Commission 2015:25; Frechtling 2013:7; Frentt \& Frechtling 2015:546). The models discussed above present other methods in which economic impacts in tourism activities can be quantified. For the purposes of this study, visitor spending surveys were used to determine the economic impact of shark cage diving in Gansbaai. Frechtling (2006:5) confirms that the findings from questions on spending surveys can present relative estimates on visitor expenditure, thus allowing visitor behaviour and profiling to be drawn.

Gansbaai is globally recognised for its exceptional shark cage diving opportunities with the majority of its visitors comprising international visitors (Marine Dynamics 2018). This article looks at the profiles of visitors who take part in shark cage diving in Gansbaai. The findings also have implications for shark cage diving operators as well as other stakeholders involved in contributing to a sustainable shark cage diving economy in Gansbaai.

Studies that have been conducted in Gansbaai mainly focus on the conservation and the possible changes in shark behaviour because of human involvement (Dyer Island Conservation Trust 2018; Johnson \& Kock 2006:42; South African Shark Conservancy 2018). Because of the lack of data which focuses on the economic impact of shark cage diving in Gansbaai, this study becomes significant as such profiling of visitors will assist in a greater understanding of contribution of shark cage diving in the area and how the destination should prepare itself to meet the needs, wants and demands related to the profile.

\section{Coastal and marine tourism, a global perspective}

Orams (1999:7) suggests that as the oceans are still considered unexplored territories in comparison to land, a growing number of activities and usage were identified. Hall (2001:604) adds that because of technological advances, it has become easier to reach the marine space as well as construct-resistant infrastructure and facilities in the oceans in order to develop several activities for economic gain. Coastal and marine tourism is a part of nature-based tourism. Orams and Lück (2014:482) state that nature-based tourism contributes to the coastal economy of many tropical marine systems around the world. Biggs et al. (2015:67) support this statement by noting that it is mostly around coral reefs and unique marine species such as sharks and whales where nature-based tourism is seemingly centred in. Such regions are, therefore, presented with opportunities to serve tourists with coastal and marine-related offerings for tourism.

\section{Coastal and marine tourism, the South African perspective}

The marine space, with a coastline stretching of over $3000 \mathrm{~km}$ serves as an integral part of the South African environment (South Africa Department of Environmental Affairs 2017). It is regarded as the country's assets and presents as well as sustains a wide range of social, ecological and economic services which form the foundation of income for millions of individuals in the country (South Africa Department of Environmental Affairs 2017). Despite this fact, research such as Operation Phakisa (2016) has identified opportunities for further utilisation of the coastal and marine environment.

Operation Phakisa (2014) is an initiative developed by the South African government to focus on the marine space of the country as a means of economic gain, particularly for previously disadvantaged communities. The aim was to unlock the potential of country's oceans that are currently underutilised as a venue for tourism activities at a 'fast' pace (Operation Phakisa 2014). Operation Phakisa (2014) predicts that South Africa's oceans are capable of generating an 
estimated R177 b contribution to the GDP by the year 2033. This highlights the economic potential of the South African marine space. The Institute of Global Dialogue (2016) also notes that there are 250000 jobs directly linked to various maritime regimes locally, but with Operation Phakisa (2014), this number could be up-scaled to a million jobs. An understanding of tourists' profile visiting Gansbaai will contribute to a better understanding of tourism activities linked to the marine environment.

\section{Profile of coastal and marine tourism visitors}

Moscardo et al. (2004:168) stress that it is of utmost importance for sustainable wildlife tourism to have a clear understanding of its visitors. Understanding the visitors will assist in designing programmes which can influence visitor behaviour and help improve the quality of their experience. The authors add that understanding their visitors will result in financial gain for operators. However, Lotter, Geldenhuys and Potgieter (2014) argue that understanding visitors and their motivations is not an easy task. The emergence of new tourist profiles continues to be a forever changing and ongoing process which stems from dynamics and changes in society (Custódio Santos, Veiga \& Águas 2016:656), further highlighting difficulty in this task.

Custódio Santos et al. (2016:656) note that implications for service providers are structured by what is known to be the three phases of the consumption process which are: pretravel, during travel and post-travel. Custódio Santos et al. (2016:660) focus on two segments which service providers should look into as visitor profiles, namely, the senior segment and the millennials. They note that the senior segment relies on more traditional methods to access information whilst the millennials have shifted towards a more digital space. They also highlight that the millennials present a more educated group with higher income, with a quest to know more and increasingly showing interest in tourism which is in harmony with the environment (Custódio Santos et al. (2016:662). Therefore, operators need to be more environmentally conscious in their approach in order to satisfy the needs of their visitors. The authors further note that although these segments have not yet been thoroughly profiled, the data available are sufficient for service providers to draft better strategies for implementation. Furthermore, the academic industry needs to produce more studies which will contribute to a better understanding of these segments. It is from this perspective that the profiles of the tourists who visit Gansbaai are explored.

\section{Research methods and design Study area}

The study was conducted in Gansbaai, an area situated in the Overberg District Municipality region, in the Western Cape Province, South Africa. The town of Gansbaai lies between Hermanus and Pearly Beach and is approximately
$170 \mathrm{~km}$ from Cape Town (Cape Town Magazine 2016). Gansbaai is regarded as the capital of great white sharks with an estimated population of 1500 sharks (The Roundhouse 2013). Currently, there are eight licensed shark cage diving operators who offer shark cage diving experiences in Gansbaai and the study was strictly limited to visitors who took part in shark cage diving.

Tourism is the main economic activity in the area and the majority of visitors come to Gansbaai for holiday purposes (Lonely Planet 2018). Moreover, the community of Gansbaai relies heavily on marine resources in order to make a living and to provide employment in the region (Overberg-Info 2018). The shark cage diving industry of Gansbaai is only for observation of great white sharks in their natural habitat to generate money for the tourism industry (South Africa Department of Environmental Affairs 2017). This practice is governed by strict legislative policies of the South African government as the great white shark is an endangered species and Gansbaai lies within the marine protected areas (MPAs) of the country (South Africa Department of Environmental Affairs 2017). Gansbaai is the only region in the world where great white sharks are viewed all year round with no seasonal restrictions (Xplorio 2017). In addition, Gansbaai also has the shortest travel distance from shore to the viewing area in the world, with a boat ride of only 15-20 min (Marine Dynamics 2016).

\section{Population and sampling}

A questionnaire is generally the first tool people consider when conducting research (Research Connections 2016). A self-administered close-ended questionnaire was distributed to visitors on a face to face basis. According to Siniscalco and Auriat (2005:23), the main advantage of close-ended questionnaires is that participants are restricted to a fixed set of questions that are relatively easy to answer. In achieving the objectives of this study, a total of $n=378$ surveys were collected, using proportionate sampling reflecting international and domestic visitors. This method is used when the population consists of various subgroups that are largely different in number and the number of subjects from each subgroup is determined by their number relative to the population (Hassan, Schattner \& Mazza 2006:70). This sampling method was useful for this study as it excluded local residents within Gansbaai from the sampling, thus randomly selecting visitors from outside the Gansbaai region. The data collection process was scheduled over a period of 3 months from a number of scheduled trips to Gansbaai.

\section{Questionnaire}

The questionnaire focused on the profile of visitors and respondents were asked about their origin, purpose of travel and group dynamics. The questionnaire also had questions relating to demographics, where respondents indicated their age, income, education and employment status. 
Prior to the data collection process, a pilot study was conducted to test the viability of the research instruments. Hassan et al. (2006:70) endorse the pilot study as one of the most important steps in a research project and is conducted to discover potential problem areas and possible errors in the research instruments prior to implementation of the actual study. The instrument was adjusted in order to collect more meaningful data. A well trained assistant fieldworker assisted in the collection and quality checks of the questionnaires. In analysing the data, the Statistical Package for Social Studies (SPSS) Version 24.0 was used.

\section{Ethical consideration}

At a meeting of the Research Ethics Committee on 21 November 2016, ethics approval was granted to Nolwazi Mabaleka (211267104) for research activities related to M.Tech: Master of Technology in Tourism and Hospitality at the Cape Peninsula University of Technology. Ethical consideration that were adhered to during the data collection process included institutional (CPUT) consent (Ref No.: 2016FBREC401) which was obtained to carry out the study as well as permission from the participating tour operators in Gansbaai. The ethical consideration mentioned above included permission from participating tour operators in Gansbaai for data collection, as well as provided anonymity and voluntary participation for the visitors. This included ensuring that there will be no harm to the participants and that the data will be treated with honesty and integrity.

\section{Results}

As indicated in Table 1, the study revealed that an overwhelming majority of the respondents (82\%) taking part in shark cage diving in Gansbaai are day visitors and 18\% of

TABLE 1: Geographic profile.

\begin{tabular}{lc}
\hline Geographic indicators & $\%$ \\
\hline Type of visitor & 18 \\
Overnight visitors & 82 \\
Day visitors & \\
Visitor origin & 10.6 \\
National & 89.4 \\
International & \\
International visitors & 42.7 \\
Europe & 21.2 \\
North America & 9.4 \\
South America & 5.6 \\
Asia & 5.6 \\
Africa (Excluding South Africa) & 4.9 \\
Oceania & \\
Domestic visitors & \\
Eastern Cape & 2.5 \\
Free State & 22.5 \\
Gauteng & 45.0 \\
KwaZulu-Natal & 17.5 \\
North West & 5.0 \\
Western Cape & 7.5 \\
\hline
\end{tabular}

them are overnight visitors. These results suggest that there was no strong motivation for overnight visits in the area. The study also revealed that an overwhelming majority (89.4\%) was international visitors and $10.6 \%$ of the visitors were domestic, strongly suggesting that this activity attracts the international market the most. Out of the international visitors, most came from Europe (42.7\%) followed by North America (21.2\%) and South America (9.4\%). These results reveal Europe as the largest market attracted to shark cage diving in Gansbaai. National visitors mainly came from Gauteng (45\%) followed by Free State $(22.5 \%)$ and KwaZuluNatal $(17.5 \%)$ - covering $85 \%$ of the respondents in the national visitor's category. As the highest number of the national visitors came from Gauteng and Free State, this brings forth an argument that shark cage diving mostly attracts visitors that come from non-coastal areas.

As presented in Table 2, the study revealed that most visitors who took part in shark cage diving were males (55.6\%) followed by females $(44.4 \%)$. The majority were single (53.3\%) followed by those who were married (46.7\%). The study also revealed that most shark cage divers were between the ages of 31 and $40(34.3 \%)$ followed by those between the ages of 21 and $30(32.7 \%)$. This shows a strong interest from the millennials group. Most visitors travelled with friends (31\%) and family (24\%). The majority (65\%) travelled to Gansbaai for holiday purposes, with a large number of the respondents taking part in a guided tour $(57.7 \%)$ followed by $41.8 \%$ who used a hired car. This projects Gansbaai as a good

TABLE 2: Demographic profile.

\begin{tabular}{lc}
\hline Demographic indicators & $\%$ \\
\hline Gender & 55.6 \\
Male & 44.4 \\
Female & \\
Marital status & 53.3 \\
Single & 46.7 \\
Married & \\
Age & 32.7 \\
21-30 & 34.3 \\
31-40 & 24.7 \\
$41-50$ & 6.1 \\
51-60 & 2.2 \\
61-70 & \\
Composition of group & 21.7 \\
Alone & 31.0 \\
Friends & 24.0 \\
Family & 12.0 \\
Family and friends & 8.0 \\
Business associates & 3.0 \\
Tour group & \\
Purpose of travel to Gansbaai & 79.8 \\
Holiday & 8.2 \\
Visit friends and family & 1.1 \\
Incentives & 10.9 \\
Fusiness & \\
Public transport & 51.8 \\
Hired car & \\
Guided tour & \\
\hline & \\
\hline
\end{tabular}


self-drive destination. Most respondents were new to marine wildlife activity meaning that they have never participated in marine-based activities prior to the current shark cage diving experience. This indicates that shark cage diving does not need past experience. Just above half of the respondents (53\%) indicated that shark cage diving was their first marine wildlife activity.

Table 3 indicates that most of the visitors were well educated as the majority of the respondents hold a university degree $(56.2 \%)$ followed by a postgraduate degree $(31.5 \%)$ and the least with secondary or primary school education (12.2\%). These results give an indication that shark cage diving attracts the educated group of individuals. The majority of the respondents were employed full time (70.2\%), followed by self-employed $(11.3 \%)$ with the least being unemployed (0.3\%). Just over half of the respondents earned between R40 001 and R50 000 (52\%) followed by R30 001 and R40 000 (19.4\%).

Table 4 depicts the reasons why people take part in shark cage diving. This assists in understanding the motivation of participating in this activity. There was a general agreement with the given statements to why people take

TABLE 3: Socio-economic profile.

\begin{tabular}{lc}
\hline Socio-economic indicators & $\%$ \\
\hline Highest level of education & 31.2 \\
Post graduate degree & 55.3 \\
University degree & 12.2 \\
Primary or secondary school & \\
Current employment status & 70.2 \\
Employment full time & 11.3 \\
Self employed & 8.8 \\
Student & 6.7 \\
Employment part time & 2.7 \\
Retired & 0.3 \\
Unemployed & \\
Monthly net income & 5.7 \\
R1-R8000 & 2.3 \\
R8001-R10 000 & 5.7 \\
R10 001-R20 000 & 14.9 \\
R20 001-R30 000 & 19.4 \\
R30 001-R40 000 & 52.0 \\
R40 001-R50 000 &
\end{tabular}

part in shark cage diving. Visitors generally want to learn more about sharks as well as the marine environment. Other visitors generally want to experience something new and escape their usual routine whilst others want to overcome fear.

\section{Discussion}

The study revealed that a majority of shark cage divers in Gansbaai are international visitors who were mainly in South Africa for holiday purposes. This is in line with Stats SA (2018) that $96.6 \%$ of visitors to the country are here for holiday purposes. The study also revealed that of the domestic visitors, the majority come from Gauteng and Free State which suggests that shark cage diving is mainly drawing visitors that come from non-coastal regions. An overwhelming majority of visitors to Gansbaai were day visitors with only a few overnight visitors. This is, therefore, a reflection that the potential of spending in the area is limited as more economic spending would be larger if overnight visits were greater. In addition, this suggests that Gansbaai is not strongly recognised as an overnight destination, thus compromising maximum potential of the area. Furthermore, visitors mainly make use of a guided tour to Gansbaai, which suggests that visitors make use of accommodation mostly in Cape Town or other areas in the Western Cape.

The number of male visitors was only slightly larger than female visitors, which suggests that female participation is increasing in activities that were perceived as maledominated. Doran (2016:59) supports this statement indicating that women are increasingly participating in adventure tourism as a tool to empower themselves. The majority of the visitors were single with the millennials group being the dominant group. The visitors mainly travelled in groups of family and friends. Most shark cage diving participants had a university degree and were employed full time, which coincides with the price of shark cage diving being relatively high. The majority of the visitors earned between R40 001 and R50 000 per month, which depicts the relationship with employment and the affordability of shark cage diving.

With regard to motivation, visitors agreed to statements which portrayed support to shark cage diving as an activity

TABLE 4: Reasons why visitors take part in shark cage diving (in \%).

\begin{tabular}{|c|c|c|c|c|c|}
\hline I take part in shark cage diving ... & Strongly disagree & Disagree & Neutral & Agree & Strongly agree \\
\hline ... to learn more about sharks & 3.7 & 8.3 & 27.2 & 46.1 & 14.7 \\
\hline ... to learn more about the marine environment of the area & 2.7 & 9.9 & 21.6 & 38.4 & 27.5 \\
\hline ... to experience the great white sharks in their natural habitat & 1.9 & 3.5 & 14.1 & 30.7 & 49.9 \\
\hline ... to see an endangered species & 2.9 & 4.5 & 17.1 & 42.4 & 33.1 \\
\hline$\ldots$ because I have an interest in sharks & 1.1 & 5.9 & 18.9 & 40.5 & 33.6 \\
\hline ... for the adrenalin rush & 4 & 6.9 & 17.9 & 38.1 & 33.1 \\
\hline$\ldots$ because shark cage diving is affordable & 10.4 & 14.1 & 24.5 & 30.4 & 20.5 \\
\hline ... to overcome fear & 16 & 10.4 & 18.9 & 33.1 & 21.6 \\
\hline ... for a new wildlife experience & 4.5 & 6.1 & 13.3 & 40.3 & 35.7 \\
\hline ... because I am crazy about shark cage diving & 7.2 & 11.5 & 25.3 & 31.7 & 24.3 \\
\hline ... to get away from my routine and try something new & 5.6 & 7 & 18.8 & 39.7 & 29 \\
\hline
\end{tabular}


to seek for new experiences. Visitors also agreed that shark cage diving gave them the opportunity to learn about an endangered species, to overcome fear, to learn about sharks as well as to fulfil their personal desires. This suggests interest in shark cage diving as well as its relationship with personal motivation.

\section{Implications}

In South Africa, there is currently limited information related to the contribution of CMT to the GDP of the country. There is also limited research focusing on the types of tourists who take part in coastal and marine related activities in order to fully design programs dedicated to their interests. This study provides an indication of the type of tourists who take part in CMT as well as their characteristics in order for operators and Gansbaai as a tourist destination to satisfy their interests. This anticipated approach may lead to an increased demand of the area and the development of new products. This will also expose other areas such as accommodation and dining for development leading to more economic benefits for the communities involved.

\section{Conclusion}

The potential of CMT in South Africa remains large and needs further research for maximum utilisation. A continuous study on profiles as well as the economic impact of CMT in other parts of the country will assist in this quest. There is a strong interest in marine-based activities, particularly from the international market and Gansbaai remains amongst the areas offering unique experiences. Shark cage diving mostly attracts the millennials group, which are highly educated and well-paid earners. This, therefore, is an implication for service providers to match or even exceed their expectations in order to generate more demand. The study highlights certain recommendations such as the need to develop a more diverse offering to complement shark cage diving in order to encourage more overnight visits in Gansbaai. This may also result in more economic activity in the area which could benefit the local businesses as well as the local community in the area due in terms of creation and tourism receipts.

\section{Acknowledgements}

The researchers would like to acknowledge the National Department of Tourism for financial support to carry out the study.

\section{Competing interests}

The authors declare that no competing interests exist.

\section{Authors' contributions}

All authors contributed equally to this work.

\section{Funding information}

This research received funding from the National Department of Tourism.

\section{Data availability statement}

New data were collected and analysed for this research.

\section{Disclaimer}

The views expressed in the article are those of the authors and not of the institution or the funder.

\section{References}

Aguiló Perez, E. \& Juaneda, S.C., 2000, 'Tourist expenditure for mass tourism markets', Annals of Tourism Research 27(3), 624-637. https://doi.org/10.1016/S01607383(99)00101-2

Bess, R. \& Ambargis, Z.O., 2011, 'Input-output models for impact analysis: Suggestions for practitioners using RIMS II multipliers', paper presented at the 50th Southern Regional Science Association conference, New Orleans, LA, 23-27th March.

Biggs, D., Hicks, C.C., Cinner, J.E. \& Hall, C.M., 2015, 'Marine tourism in the face of global change: The resilience of enterprises to crises in Thailand and Australia',
Ocean and Coastal Management 105(1), 65-74. https://doi.org/10.1016/j. ocean and Coastal Manan.2014.12.019

Cape Town Magazine, 2016, Shark cage diving with white shark diving company in Gansbaai, viewed 12 August 2019, from http://www.capetownmagazine.com/ extreme/shark-cage-diving-with-white-shark-diving-company-in-gansbaai/ 137_52_1155.

Custódio Santos, M., Veiga, C. \& Águas, P., 2016, 'Tourism services: Facing the challenge of new tourist profiles', Worldwide Hospitality and Tourism Themes 8(6), 654-669. https://doi.org/10.1108/WHATT-09-2016-0048

Doran, A., 2016, 'Empowerment and women in adventure tourism: A negotiated journey', Journal of Sport and Tourism 20(1), 57-80. https://doi.org/10.1080/147 75085.2016.1176594

Dyer Island Conservation Trust, 2018, History of the trust, viewed 12 November 2018 , from https://www.dict.org.za/\#dict.

European Commission, 2015, Guide to cost benefit analysis of investment projects, European Commission, Brussels.

Fernando, S., Bandara, J.S., Smith, C. \& Pham, T., 2015, SLCGE - Tourism: A computable general equilibrium model of the Sri Lankan economy for tourism policy analysis, Griffith University, Brisbane.

Frechtling, D.C., 1994, 'Assessing the economic impacts of travel and tourism Introduction to travel economic impact estimation', in B. Ritchie \& C.P. Goeldne (eds.), Travel, tourism and hospitality research: A handbook for managers and researchers, pp. 427-445, John Wiley, New York, NY.

Frechtling, D.C., 2006, 'An assessment of visitor expenditure methods and models', Journal of Travel Research 45(1), 26-35. https://doi.org/10.1177/00472875062 88877

Frechtling, D.C., 2013, The economic impact of tourism: Overview and examples of macroeconomic analysis, World Tourism Organisation, Madrid.

Frentt, C. \& Frechtling, D.C., 2015, 'Assessing a tourism satellite account: A programme for ascertaining conformance with United Nations standards', Tourism Economics 21(3), 543-559. https://doi.org/10.5367/te.2014.0368

Gansbaai Info, 2016, Shark cage diving, viewed 12 May 2018, from http://gansbaaiinfo com/activities/shark-cage-diving/.

Grant Thornton Report, 2018, Travel, tourism and leisure, viewed 22 May 2018, from https://www.grantthornton.co.za/industry/Travel-tourism-leisure/.

Hall, C.M., 2001, 'Trends in ocean and coastal tourism: The end of the last frontier?', Ocean and Coastal Management 44(9-10), 601-618. https://doi.org/10.1016/ S0964-5691(01)00071-0

Hassan, Z.A., Schattner, P. \& Mazza, D., 2006, 'Doing a pilot study: Why is it essential?', Academy of Family Physicians of Malaysia 1(2\&3), 70-73.

Institute for Global Dialogue, 2016, Toward a South and Southern African integrated oceans governance framework: South Africa's leadership dilemmas in promoting a global South dialogue on governance in the Indian and South Atlantic oceans, Institute for Global Dialogue, Pretoria.

Johnson, R. \& Kock, A., 2006, 'South Africa's white shark cage-diving industry - Is their cause for concern?', in D.C. Nel (ed.), Finding a balance: White shark conservation and recreational safety in the inshore waters of Cape Town, WWF SA, Cape Town.

Lange, G.M. \& Jiddawi, N., 2009, 'Economic value of marine ecosystem services in Zanzibar: Implications for marine conservation and sustainable development', Ocean and Coastal Management 52(10), 521-532. https://doi.org/10.1016/j. ocecoaman.2009.08.005

Lonely Planet, 2018, Welcome to Gansbaai, viewed 12 June 2019, from https://www. lonelyplanet.com/south-africa/gansbaai.

Lotter, M.J., Geldenhuys, S. \& Potgieter, M., 2014, 'Adventure tourists in Pretoria South Africa: A demographic profile', African Journal of Hospitality, Tourism and Leisure 3(2), 1-10.

Marine Dynamics, 2016, Shark cage diving Cape Town, viewed 10 October 2017, from http://www.sharkwatchsa.com/en/sharks/cape-town-shark-cagediving/. 
Marine Dynamics, 2018, Shark cage diving in Gansbaai - South Africa, viewed 12 November 2019, from http://www.sharkwatchsa.com/en/home/?utm campaign=Branded\&utm source=google-cpc\&utm medium $=$ b\&utm

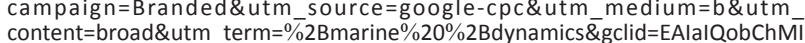
content=broad\&utm term $=\% 2$ Bmarine $\% 20 \% 2 B d y n$
kp2plrjW4AIVjZXtCh38GgjMEAAYASAAEgJnsvD_BwE.

Marques, C., Reis, E. \& Menezes, J., 2010, 'Profiling the segments of visitors to Portuguese protected areas', Journal of Sustainable Tourism 18(8), 971-996. https://doi.org/10.1080/09669582.2010.497222

Mihajlovic, I. \& Koncul, N., 2016, 'Changes in consumer behavior: The challenges for providers of tourist services in the destination', Economic Research 29(1) 914-937. https://doi.org/10.1080/1331677X.2016.1206683

Mograbi, J. \& Rogerson, C., 2007, 'Maximising the local pro-poor impacts of dive tourism: Sodwana Bay, South Africa', Urban Forum 18(2), 85-104. https://doi. org/10.1007/s12132-007-9002-9

Moscardo, G., Woods, B. \& Saltzer, R., 2004, 'Wildlife tourism: Impacts, management and planning', in K. Higginbottom (ed.), The role of interpretation in wildlife tourism, pp. 231-249, Common Ground Publishing, Altona.

Operation Phakisa, 2014, Oceans economy: Coastal and marine tourism, viewed 29 August 2018, from http://www.operationphakisa.gov.za/Pages/Home.aspx.

Operation Phakisa, 2016, Marine Protection Service and Ocean Governance, viewed n.d., from https://www.operationphakisa.gov.za/operations/oel/pmpg/Pages/ default.aspx.

Orams, M., 1999. Trends and changes in the whale-watching industry in Vava'u 1999-2009, AUT University, Auckland.

Orams, M. \& Luck, M., 2014, 'Coastal and marine tourism: Emerging issues, future trends and research priorities', in A.A. Lew, C.M. Hall \& A. Williams (eds.), The Wiley Blackwell companion to tourism, pp. 479-489, John Wiley \& Sons, Hoboken, NJ.

Overberg-Info, 2018, General information on Gansbaai, viewed 13 June 2019, from https://www.overberg-info.co.za/region/town/186.
Research Connections, 2016, Assessing research quality, viewed 20 April 2019, from https://www.researchconnections.org.icpsrweb/content/childcare/understand/ researchquality.htm.

SA Venues, 2016, Shark cage diving in South Africa, viewed 12 August 2019, from http://www.sa-venues.com/activities/shark-cage-diving.htm.

Siniscalco, M.T. \& Auriat, N., 2005, Quantitative research methods in educational planning. Module 8: Questionnaire design, UNESCO, Paris, viewed 10 Novembe 2017, from https://unesdoc.unesco.org/ark:/48223/pf0000214555.

South Africa Department of Environmental Affairs, 2017, Policy on white shark cage diving, Department of Environmental Affairs, Pretoria.

South African Maritime Safety Authority (SAMSA), 2016, Operation Phakisa (Ocean Economy) goes full steam ahead, Eastern Cape steals national limelight on progress of South Africa maritime economic sector development, viewed 10 January 2019, from https://blog.samsa.org.za/2016/04/08/operation-phakisaocean-economy-goes-full-steam-ahead/.

South African Shark Conservancy, 2018, More than just sharks, viewed 12 July 2019, from https://www.sharkconservancy.org.

Statistics South Africa, 2018, Statistical release P0351: Tourism and migration viewed 24 March 2018, from http://www.statssa.gov.za/publications/P0351/ P0351February2018.pdf.

Stynes, D.J., 1997, Economic impacts of tourism, Midlands State University, viewed 05 September 2018, from https://www//msu.edu/course/prr/840/econimpact/pdf/ ecimpvol1.pdf.

The Roundhouse, 2013, Shark cage diving Gansbaai, viewed 12 September 2018 from https://www.theroundhouse.co.za/shark-cage-diving-gansbaai/.

Vainikka, V., 2013, 'Rethinking mass tourism', Tourist Studies 13(3), 268-286. https:// doi.org/10.1177/1468797613498163

Xplorio, 2017, Great white shark hotspots, viewed 15 July 2018, from https://xplorio. com/gansbaai/en/about/infographic/great-white-shark-hotspots/. 